\title{
Lateral
}

Journal of the Cultural Studies Association

\section{Review of What's the Use?: On the Uses of Use by Sara Ahmed (Duke University Press)}

by Caroline Kinderthain | Book Reviews, Issue 9.2 (Fall 2020)

\begin{abstract}
The last book in Ahmed's terminological trilogy, What's the Use investigates a term rooted in quotidian routine: use. Her previous books in this series, The Promise of Happiness (2010) and Willful Subjects (2014), interrogate happiness and the will respectively. Following her resignation from Goldsmiths University, What's the Use highlights both the complexity of taking on use as a concrete project and the lasting effects of stopped university work. By leading the reader through an intellectual, philosophical, and educational history of "use," Ahmed attaches "use" and the human experience to diversity work in the university. With student and faculty complaints as her evidence, Ahmed provides heart-breaking, anxiety-inducing, enraging testimonials of systemic oppression, ignorance, and abuse in the university setting. What's the Use provides tangible practices for disrupting overused systemic oppression in a referential tome that can be used as both a study guide and a road map.
\end{abstract}

KEYWORDS higher education, queer, university

What's the Use?: On the Uses of Use By Sara Ahmed. Durham: Duke University Press, 2019, pp. 296. ISBN: 978-1-4780-0650-3 (paperback). US List \$26.95.

The last book in Ahmed's terminological trilogy, What's the Use investigates a term rooted in quotidian routine: use. Her previous books in this series, The Promise of Happiness (2010) and Willful Subjects (2014), interrogate happiness and the will respectively. Ahmed describes the process of writing these earlier texts as, "following words around, in and out of their intellectual histories." (31, my emphasis) What's the Use demands a different kind of process: not only is "use" the method, as in "using happiness" or "the use of the will," but it is also the subject, as in the thing that is used, thus leading this project to turn from "in and out" to "around and about." Ahmed also notes that an earlier approach to the same kind of archival work from her previous project would not fit here, and instead a "used archive" replaced a "useful" one for the research purposes of this book. (13) Situating "use" in past research around a present context is indicative of not only where this project will go, but how it came to be. While research for Use began in 2013 before Willful Subjects, Ahmed did not return to it until 2016, due to her involvement in "a series of inquiries into sexual harassment and sexual misconduct" that resulted in her resignation from Goldsmiths University. (12) According to Ahmed's personal website, her resignation was in retaliation to the university's "failure to deal with the problem of sexual harassment."1- The distance between the start of her research and the first draft highlights both the complexity of taking on use as a concrete project and the lasting effects of stopped university work. By leading the reader through an intellectual, philosophical, and educational history of "use," Ahmed attaches "use" and the human experience to diversity work in the university. 
In the first chapter, Ahmed explores objects and their "use status," the way that objects travel through time in relation to how, when, and where they are used. (23) She identifies moments of "created use" in objects like a cup or a puddle, which establish an understanding that "use can come after" and does not have to reside in the present. A puddle becomes a drinking vessel only after Ahmed's dog, Poppy, drinks from it. (23) In other words, an object's usefulness does not rely on its potential to follow the purpose for which it was designed. Throughout the rest of this chapter, subject headings indicate the temporal journey of use: In Use, Used, Unused, Overused, Used Up, and Un/Usable. These headings signify the modes of use that Ahmed explores in reference to particular objects and serve as a chiasmic index for her final chapter, in which she fits moments of university work (and usually stopped university work) into these same categories.

University work consists of any function of a university that is challenged by normative narratives of operation. The fundamentals of university life - that students are able to learn and graduate in a safe environment-are only truly achievable if every individual of race, gender, orientation, and ability is able to ensure their own safety. Ahmed unfolds how students are stopped when modes of use are deemed unusable according to the infrastructure in place. Like this book's title, Ahmed constantly asks questions of use assumptions: Who are use instructions intended for, with respect to social and political categories? (30) How does a public space become unusable? (31) What happens when we take something out of use for preservation? (33) To end chapter one, Ahmed introduces an image of a "well-worn path" from a British travel guide alongside a kind of use-paradox: "The more a path is used, the more a path is used." (41) As a path is overused, it becomes solidified as the only possible path, thus making change and reformation difficult. In her later chapters, she will use "the path" as a relation of institutions, a formulation for utilitarianism and universal design, and a catalyst for potential queer use.

Ahmed reanimates the history of biology and the theory of life, allowing her to stabilize "use" in phenomena. (69) She provides the reader with an encyclopedic overview of both Jean Baptiste Lamarack's and Charles Darwin's notes on biological law and evolution, which include or identify particular moments of use. Ahmed puts Lamarack and Darwin in conversation with each other, as comparing the two "provides a particularly effective case study of the uses of use because the differences and similarities between them have already been framed in these terms." (69) Her analysis furthers a question of what power, if any, environments can hold over usability, which is the fundamental point from which Darwin and Lamarck diverge. For Lamarack, the ever-changing nature of an environment demands dynamic changeability for humans. (72) Darwin recognizes this same changeability but credits it to innate biological natural selection. (80) Ahmed weaves these 'use arguments' together to challenge the tendency to view the fungibility of human nature as dependent on physical ability. If an environment demands certain modes of usability, like a giraffe's long neck reaching tall tree leaves, how can individuals practice autonomy within certain factors deemed out of their control? To end the book's second chapter, Ahmed draws from a Marxist critique of productivity, that commodified labor requires, "a history of exhaustion," to contest eugenic conclusions of the "moral duty" of use. (95) Failing to live up to the expectation of exhaustion exposes how a person can be deemed useless by association to normative ability. (102)

In chapter three, Ahmed again stabilizes "use" by uncovering its core relation to utilitarianism, discipline, and education theory, including analysis of a range of writers that signal these interrelated fields like Foucault, Locke, Bentham, Bell, and Lancaster. Linking education philosophy to a conversation of use sounds like a simple task. However, Ahmed 
resists the urge to remove a larger political conversation about citizen surveillance and disciplinary power from the utility of such philosophies. She introduces the early British pedagogy of monitorial schools, schools that operate with student monitors as the main disciplinarians. Such monitors would report back to the schoolmaster if fellow students were misbehaving or failing to be on task. Ahmed links monitorial policy together with positive affect as a technique of surveillance that pairs with the law of exercise-not only is a behavior rewarded for being repeated, but also for resulting in positive effects, in this case, not being reported by fellow class monitors. (120) She further frames monitorial and utilitarian pedagogy as leading children toward "useful ends." To end chapter three, Ahmed examines the connection between life and death according to Bentham's description of unemployment, in which not to work is to be dead. (136) A body's use then can be politicized based on the societal demand that it lives or dies, which leads Ahmed to complicate our understanding of the "universal value" of utility (138).

Chapter four and the conclusion ignite the present temporality of use and the university. By calling back to the details, images, and theories from history mapping in the first part of the book, Ahmed seamlessly integrates the kinds of damaging use relations that are far from stuck in the past. Diversity work for Ahmed is a clear indicator of the embodiment of a system of education that rarely veers from the "well-used paths." With student and faculty complaints as her evidence, Ahmed provides heart-breaking, anxiety-inducing, enraging testimonials of systemic oppression, ignorance, and abuse in the university setting. Objects' use-statuses are complicated as doors become closed conversations, walls become policy enforcers, and cups of tea become hush agreements (180-9). Chapter four leads into the conclusion of "queer use," using something as it was not intended to be used, as a tool for "dismantling projects here," a "here" in which readers can feel like they might have a role in tackling these well-used systems with Ahmed, not just watching from afar. (196)

While students and scholars of queer theory, feminist theory, and literary critique may have already had this book on their reading lists, Ahmed's approach to use is interdisciplinary and accessible, making its potential audience anyone who has connections within or adjacent to a university setting. What's the Use provides tangible practices for disrupting overused systemic oppression in a referential tome that can be used as both a study guide and a road map.

\section{Notes}

1. Sara Ahmed, "Bio," personal website, accessed July 1, 2020, https://www.saranahmed.com/bio$\mathrm{cv}<$ https://www.saranahmed.com/bio-cv> . D

\section{Author Information}

\section{Caroline Kinderthain}

Caroline Kinderthain is a first-year master's student in English at Clemson University. Her research focuses on queer theory and queer of color critique, 
with a special interest in how modes of queer performance and world-making are shaped by cultural influences of social media and digital community building.

View all of Caroline Kinderthain's articles.

\section{Article details}

Caroline Kinderthain, "Review of 'What's the Use?: On the Uses of Use' by Sara Ahmed (Duke University Press)," Lateral 9.2 (2020).

https://doi.org/10.25158/L9.2.7

This content is licensed under a Creative Commons Attribution-NonCommercial 4.0 International License. Copyright is retained by authors.

Lateral is the peer-reviewed, open access journal of the Cultural Studies Association.

ISSN 2469-4053 